\title{
Polyaniline/Palm Oil Blend for Anticorrosion of Mild Steel in Saline Environment
}

\author{
Mohd Rashid, ${ }^{1}$ Suhail Sabir, ${ }^{1}$ Afidah A. Rahim, ${ }^{2}$ and Umesh Waware \\ ${ }^{1}$ Department of Chemistry, AMU, Aligarh 202002, India \\ ${ }^{2}$ School of Chemical Sciences, Universiti Sains Malaysia, 11800 Minden, Malaysia \\ ${ }^{3}$ Department of Mechanical and Industrial Engineering, Qatar University, P.O. Box 2713, Doha, Qatar \\ Correspondence should be addressed to Mohd Rashid; rashidchem@gmail.com
}

Received 19 August 2013; Revised 5 December 2013; Accepted 19 December 2013; Published 17 February 2014

Academic Editor: Atilla Cihaner

Copyright (C) 2014 Mohd Rashid et al. This is an open access article distributed under the Creative Commons Attribution License, which permits unrestricted use, distribution, and reproduction in any medium, provided the original work is properly cited.

\begin{abstract}
The corrosion protective performance of polyaniline/palm oil (PAni-PO) blend coated on mild steel in $3 \% \mathrm{NaCl}$ aqueous solutions has been evaluated by electrochemical methods, namely, open circuit potential (ocp), potentiodynamic polarization, and EIS spectroscopy. The surface of mild steel was covered by a dark green protective layer due to the physical interaction between the coating and steel. The permanent shifts of ocp and potentiodynamic polarization towards higher positive value of oxidation potential by about $800 \mathrm{mV}$ and by a decrease in corrosion current density by sixfold in magnitude and an increase of 10 orders of magnitude in charge transfer resistance are due to protective coating.
\end{abstract}

\section{Introduction}

Polyaniline has been widely studied as being the most conducting and efficient corrosion inhibitor containing $\pi$-bond molecular structure under conjugation [1]. The pioneer work of DeBerry [2] had studied the elecyrodeposition of polyaniline on mild steel in a strong acid environment and observed the passivation of pure iron by a layer of polyaniline; the corrosion potential was shifted towards the more noble metal. The corrosion current density was significantly reduced at the corrosion potential. The conducting polymers have been the good candidates for protection for metals against corrosion [3-5]. Polyaniline (PAni) is probably the most vital industrial conducting polymer due to its ease of synthesis, high processability, low-synthetic cost, and environmentally stable behavior. Many papers have been published on the corrosion protection of carbon steel by polyaniline-based material [6-25]. The formation of oxide layer by passivation of iron and the reactions sequence were reported by Wessling [19]. Yao et al. [20] reported the corrosion inhibition of carbon steel by polyaniline nanofibres prepared by interfacial polymerization. The polyaniline is highly insoluble in most of the conventional organic solvents and water, restricting its use as a coating material. Sathiyanarayanan et al. [21] studied that soluble poly(ethoxyaniline) behaved as a corrosion inhibitor of iron in acidic medium. Polyaniline solutions are more effective in corrosion protection than aniline at 75-100 ppm for mild steel. Thompson et al. [22, 23] reported significant corrosion inhibition of mild steel exposed to saline $3.5 \%$ $\mathrm{NaCl}$ ) and acidic environment; the working electrode was coated by polyaniline. Wessling reported that the dispersions of doped polyaniline acted as corrosion inhibitor for mild steel, stainless steel, and copper were passivated by repeatedly dipping clean surfaces of the metals conditions. Polyaniline induces the formation of an oxide layer on mild steel and led the passivation of metal surface [7]. These fascinating results of Thompson and Wessling encourage us to investigate the corrosion protection of mild steel provided by palm oil based coating of polyaniline in saline $(3 \% \mathrm{NaCl})$ solution. The anticorrosion property of polyaniline/palm oil blend has never been reported in the literature to the best of our knowledge. In this paper polyaniline/palm oil blend coatings were applied without using any solvent or resin.

\section{Materials and Methods}

Aniline (analytical grade) was used without further purification as received from $\mathrm{BDH}$, England. $\mathrm{NaCl}$ used was used 
as received from Aldrich. Ammonium persulfate was used as received from R\&M Chemicals; U.K. Aqueous solutions were prepared from the ultrapure double-distilled water. Palm oil was procured from super market Tesco (Penang Malaysia).

2.1. Synthesis of Polyaniline/Palm Oil Coatings. The typical procedure involved in the synthesis of polyaniline/palm oil based coating is as follows: $5 \mathrm{~mL}$ of aniline $(0.05 \mathrm{M}, 0.1 \mathrm{M}$, and $0.2 \mathrm{M}$ ) was dissolved in $100 \mathrm{~mL}$ of $0.1 \mathrm{M} \mathrm{HCl}$ in three conical flasks and $2 \mathrm{~mL}$ of palm oil was added to each solution and stirred for some time to get three different blends (PAni-PO1, PAni-PO-2, and PAni-PO-3) separately for the coating. To initiate the polymerization, $20 \mathrm{~mL}$ freshly prepared solution of ammonium persulfate $(0.1 \mathrm{M})$ dissolved in $0.1 \mathrm{M} \mathrm{HCl}$ was slowly added with continuous stirring on a magnetic stirrer at room temperature of $22-24^{\circ} \mathrm{C}$ for 30 minutes. The transition in color change was observed for the reaction mixture which indicated the onset of polymerization reaction. There was an appearance of light green color within minutes and it gradually changes from green to dark green in color within 15 minutes. Finally, the dark green colored dispersion of polyaniline was obtained. The precipitate was collected after $48 \mathrm{hr}$ by filtration using filter paper number 42 and washed with distilled water, acetone and followed by drying under vacuum at room temperature. The double-distilled water was used throughout the experiment. The polyaniline/palm oil based composite (jelly-like) as synthesized by above mentioned procedure was applied physically on the mild steel sample with solvent free coatings of uniform thickness of approx. $250 \mu \mathrm{m}$ and allowed to dry in the oven at $50^{\circ} \mathrm{C}$ for proper adhesion.

2.2. Electrochemical Studies. The experiments were designed with conventional three electrodes cell assembly using Potentiostat/Galvanostat/ZRA (Gamry, Reference 600). The working electrode was a mild steel sample of radius $1 \mathrm{~cm}$ with the rest being covered with araldite epoxy and the platinum wire was used as a counter electrode and SCE as a reference electrode. The polishing of working electrode was carried out by different grades emery papers and subsequently washed and degreased by distilled water and acetone, respectively. The working electrode has been coated with as-synthesized polyaniline/palm oil based composite having different concentration of polyaniline. The open circuit, electrochemical impedance, and potentiodynamic measurement were carried out in $3 \% \mathrm{NaCl}$ solution after the open circuit potential of the system was stabilized in half an hour. The polarization was carried out at cathodic potential of $-0.3 \mathrm{~V}$ to an anodic potential of $+0.3 \mathrm{~V}$ with respect to the corrosion potential at a sweep rate of $1 \mathrm{mV} \mathrm{s}^{-1}$. The Tafel plots of anodic and cathodic curves were extrapolated to corrosion potential to get the values of corrosion current, $I_{\text {corr }}$. Electrochemical impedance measurements were carried out at open circuit potential after immersing the mild steel specimen in experimental solution in the frequency range $10 \mathrm{KHz}$ to $0.1 \mathrm{~Hz}$. Applied voltage of sinusoidal wave was $10 \mathrm{mV}$.

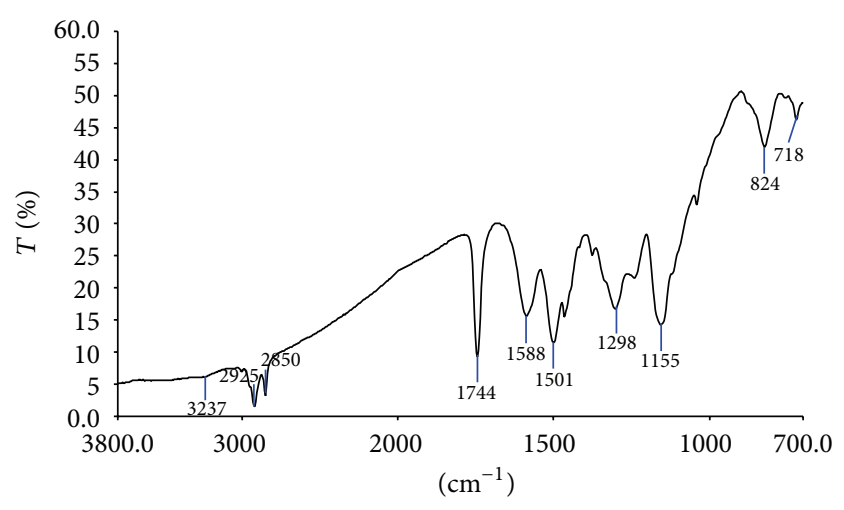

FIGURE 1: FTIR spectrum of as-synthesized palm oil based polyaniline in $0.1 \mathrm{M}$ hydrochloric acid.

\section{Results and Discussion}

3.1. IR Spectroscopy. The polymer was characterised by recording Fourier Transform Infrared Spectroscopy (FTIR) spectrum using Perkin-Elmer-2000 system (USA) with $\mathrm{KBr}$ pellet. Figure 1 shows the FTIR spectrum of the polymer; the major absorption peak at $1588 \mathrm{~cm}^{-1}$ is attributed to nitrogenquinoid unit in the ring structure and peak observed at $1501 \mathrm{~cm}^{-1}$ corresponds to benzenoid unit in the structure. The bands appear at $1298 \mathrm{~cm}^{-1}$ attributed to the stretching of C$\mathrm{N}$. The $\mathrm{C}-\mathrm{H}$ out-of-plane bending mode has been a key to identify the type of substituted benzene. The characteristic band at $824 \mathrm{~cm}^{-1}$ is observed as a single band in polyaniline salt $[21,26]$. A broad and weak peak at $3237 \mathrm{~cm}^{-1}$ is assigned to the free $\mathrm{N}-\mathrm{H}$ stretching. In addition, it is observed that some peaks are also visible in the frequency range 2800$3000 \mathrm{~cm}^{-1}$, assigned to the absorbance of methylene asymmetric and symmetric stretching vibrations, which confirm that the palm oil has chemical bond formation with PAni. A characteristic peak at $1744 \mathrm{~cm}^{-1}$ is observed for carbonyls stretching vibration of $\mathrm{C}=\mathrm{O}$ group present in palm oil.

3.2. Open Circuit Potential Measurement. Figure 2 (dash lines) shows the open circuit potential of mild steel electrode with and without the presence of corrosion inhibitor exposed to $3.0 \% \mathrm{NaCl}$ solution for $30 \mathrm{mins}$ The corrosion is controlled by monitoring the oxidation or passivation of the metal surface. The shifting of open circuit potential towards the more positive potential value indicates that increasing the thickness of coating of PAni-PO-1, PAni-PO-2, and PAni-PO3 , on top of the sample and makes it more passivized and it behaves predominantly as an anodic inhibitor.

3.3. Potentiodynamic Study. Figure 3 shows the potentiodynamic polarization curves for three different coatings on mild steel in contact with $3 \% \mathrm{NaCl}$ aqueous solution saturated with air. The formation of a passive oxide layer on mild steel in the curves is formed clearly with coating containing PAni-PO-1, PAni-PO-2, and PAni-PO-3 while there is no tendency for passivation without PAni-PO. It is clear that the formation of the oxide layer results in the decrease 


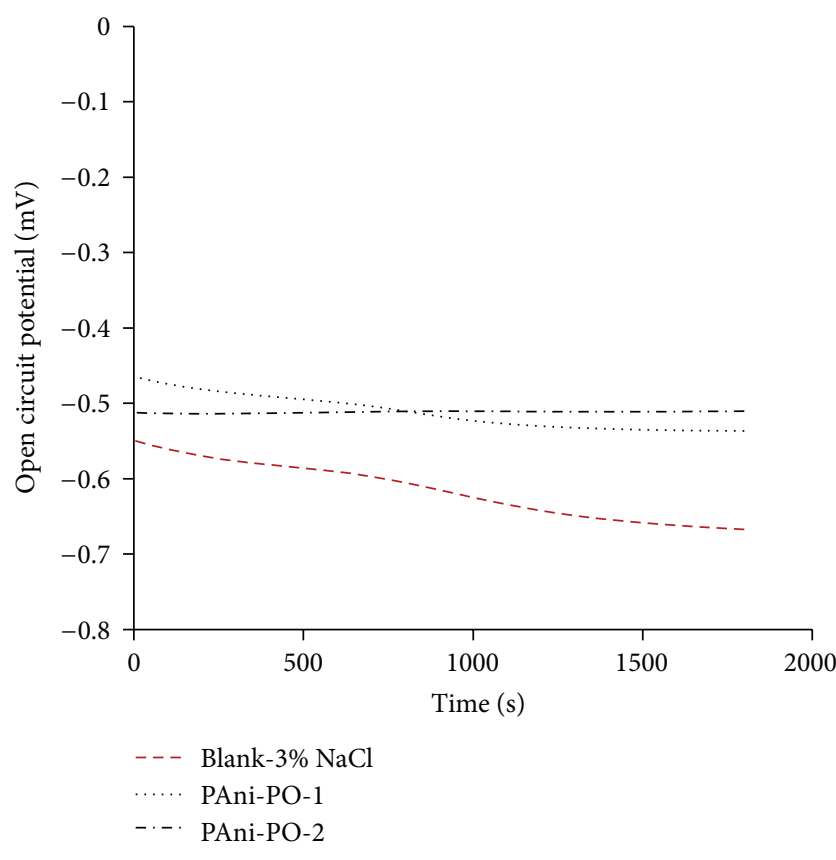

FIgUre 2: Potential-time curve of PAni-PO coating on mild steel as function of concentration and time.

of corrosion rates by many folds. Both active and passive behaviors are more pronounced in saline environment of $\mathrm{NaCl}$. The mild steel coated with PAni-PO did not show active/passive behavior. However, the mild steel with PaniPO exhibits a very significant reduction in corrosion current density. These results showed very clear evidence of the significant corrosion protection exhibited to bare mild steel sample mechanically coupled to PAni-PO coatings [7]. The corrosion kinetics parameters extrapolated from these curves are given in Table 1. There is shift in the corrosion potential towards the direction of noble metal from -750 to $-400 \mathrm{mV}$ and the redox current density was decreased by about five orders of magnitude as compared to mild steel. A significant difference was observed for the two coatings with different PAni-Palm oil compositions.

3.4. Impedance Measurements. Figures 4(a)-4(c) show the Nyquist representation of the impedance values for mild steel in $3.0 \% \mathrm{NaCl}$ in the presence of different concentrations of polymer. Impedance measurement that provides various parameters such as charge-transfer resistance $\left(R_{\mathrm{ct}}\right)$ and double layer capacitance $\left(C_{\mathrm{dl}}\right)$ is shown in Table 2. The $R_{\mathrm{ct}}$ values are calculated from the difference in impedance at lower and higher frequency as reported by Haruyama and Tsuru [27]. The Randles circuit (Figure 5) is used as an equivalent circuit where $R_{s}$ is the solution resistance, $C_{\mathrm{dl}}$ is the double layer capacitance, and $R_{\mathrm{ct}}$ is the charge transfer resistance using ZSimp Win Demo 3.2 d Software. The values extrapolated from Nyquist plots are listed in Table 2. It is clear from the observed data that the $R_{\mathrm{ct}}$ decreased from the value of 336.8 to $3542 \Omega \mathrm{cm}^{2}$ and $C_{\mathrm{dl}}$ values decrease from $1.201 \times 10^{-3}$ to $8.986 \times 10^{-6} \mathrm{Fcm}^{-2}$. The slightly depressed

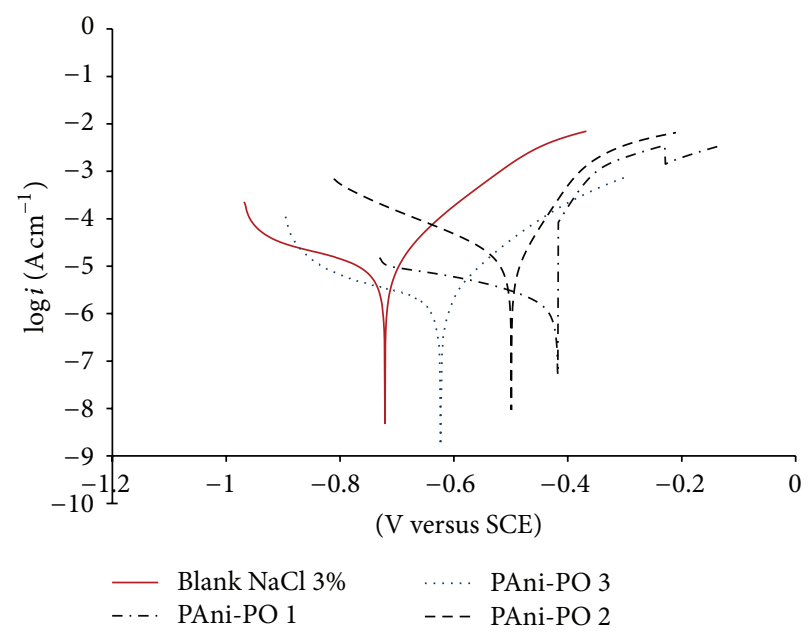

FIGURE 3: Potentiodynamic polarization curves for carbon steel without and with PAni-PO coating, in the presence of $3 \% \mathrm{NaCl}$ aqueous solution.

semi-circle and decrease in the length of the diameter of the semicircle with coating of palm oil/polyaniline blend of different composition indicated lower rates of corrosion. The centre of the semicircle below the $x$-axis signifies the existence of microroughness at the surface of metal during the corrosion process $[22,23,28-30]$. Single semicircle predicts the occurrence of single charge transfer in the process and further increase or change in concentration of polyaniline in the blend does not affect the corrosion inhibition. The diameter of semicircle in the Nyquist plot tends to increase with the increase of polyaniline up to a certain limit and further addition of polyaniline coating on the top of the mild steel has no effect in the protection of the sample. Similar shape of semicircles predicted that inhibition of corrosion followed the same mechanism of corrosion inhibition. Bode plot are shown in Figures $4\left(a^{\prime}\right)-4\left(c^{\prime}\right)$ the presence of one phase maximum was observed at intermediate frequencies, which indicated the presence of one time constant corresponding to the impedance of the formed protective coating [31]. The values of CPE decrease with the increase of in PAni-PO composition, which consequently may decrease the electrical capacity and/or increase the thickness of the electrical double layer [32].

\section{Conclusion}

The coatings containing polyaniline/palm oil blend could provide excellent protection for very thin layer when coated onto mild steel which clearly indicates that it can provide significant corrosion protection to mild steel exposed to the saline environment of $\mathrm{NaCl}$. The data assessed from results of potentiodynamic study predicts that the protection is mainly due to anodic polarization and EIS measurement clearly confirms that the potentiodynamic measurements are in good agreement with EIS spectroscopy data simulated. This coating formulation is more advantageous and easy as it does not involve the use of any organic solvent or supporting 
Nyquist plots

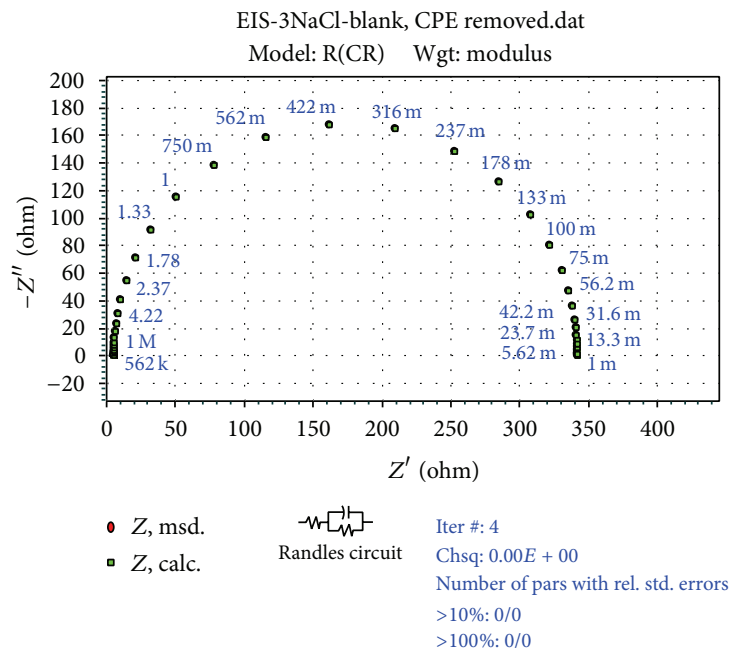

(a)

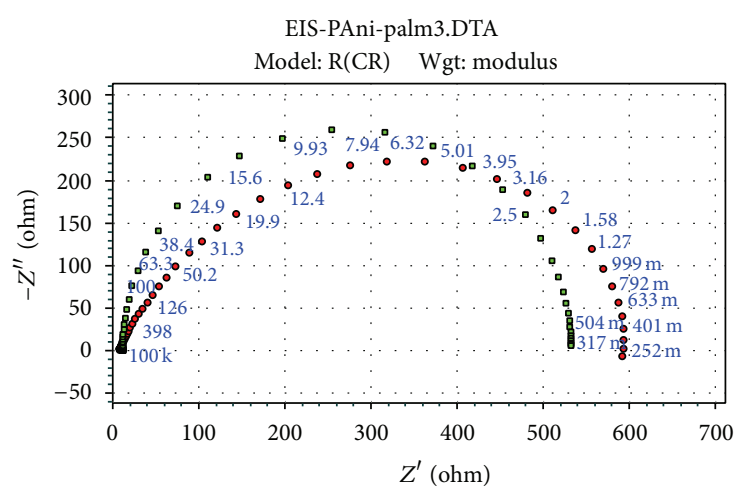

$\begin{array}{lll}-Z \text {, msd. } & \text { Iter \#: } 4 \\ \text { - } Z \text {, calc. } & \text { Randles circuit } & \text { Chsq: } 8.00 E-02 \\ & & \text { Number of pars with rel. std. errors } \\ & & >10 \%: 0 / 3 \\ & >100 \%: 0 / 3\end{array}$

(b)

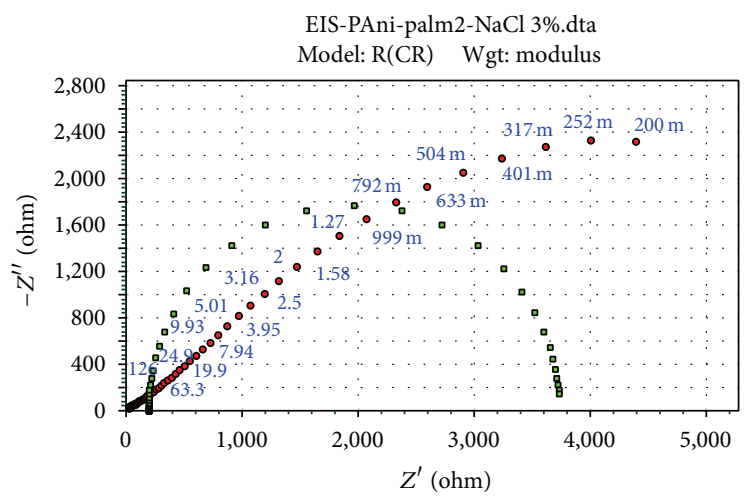

- $Z$, msd. Iter \#: 4

- $Z$, calc. Randles circuit Chsq: $3.36 E-01$

Number of pars with rel. std. errors $>10 \%: 3 / 3$ $>100 \%: 0 / 3$

(c)
Bode plots

EIS-3NaCl-blank.dta

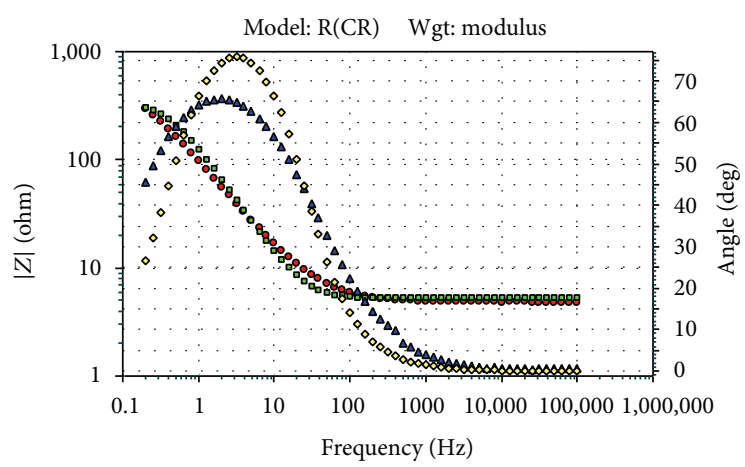

- $|Z|$, msd. $\Delta$ Angle, msd.

- $|Z|$, calc. $\quad$ Angle, calc. Randles circuit Chsq: $3.56 E-02$

Number of pars with rel. std. errors $>10 \%: 0 / 3$ $>100 \%: 0 / 3$

$\left(\mathrm{a}^{\prime}\right)$

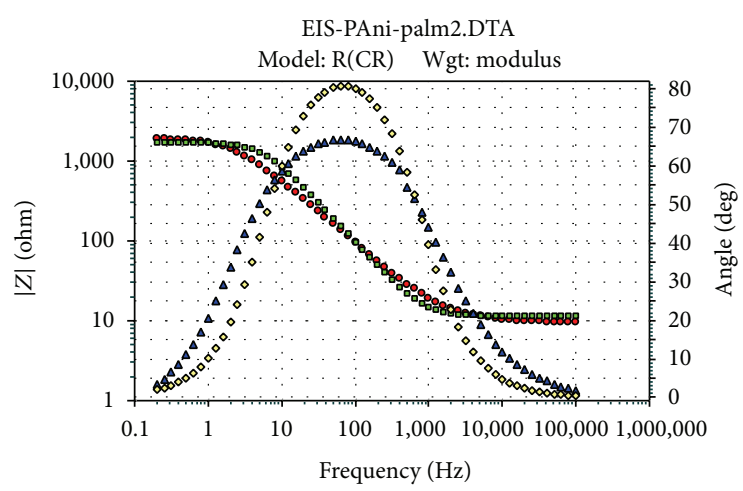

- $|Z|$, msd. $\Delta$ Angle, msd. Iter \#:4

- $|Z|$, calc. $\quad$ Angle, calc. Randles circuit Chsq: 6.06E-02

Number of pars with rel. std. errors $>10 \%: 0 / 3$ $>100 \%: 0 / 3$

$\left(\mathrm{b}^{\prime}\right)$

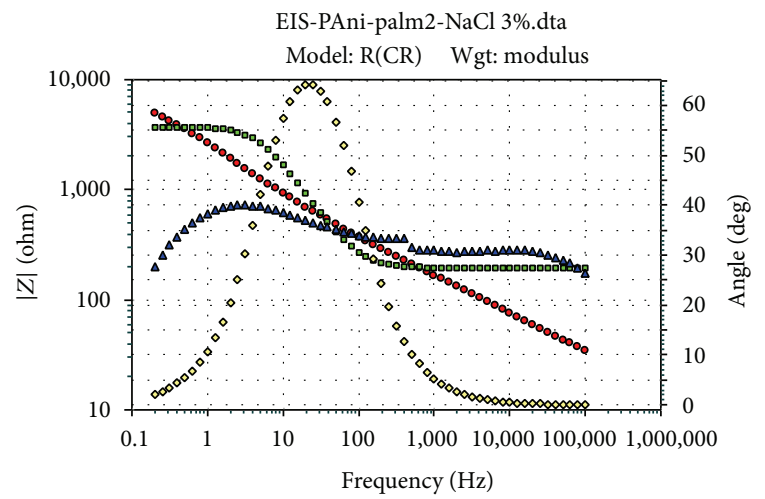

- $|Z|$, msd. $\Delta$ Angle, msd.

- $|Z|$, calc. $\quad$ Angle, calc. Randles circuit Chsq:3.36E-01

Number of pars with rel. std. errors $>10 \%: 3 / 3$

$>100 \%: 0 / 3$

$\left(c^{\prime}\right)$

Figure 4: ((a)-(c)) and $\left(\left(a^{\prime}\right)-\left(c^{\prime}\right)\right)$ show the Nyquist and Bode plot of mild steel, without and with coating of palm oil/polyaniline blend in $3 \% \mathrm{NaCl}$ solution, respectively. 
TABle 1: Corrosion kinetics parameters derived from the potentiodynamic curves of mild steel in $3 \% \mathrm{NaCl}$ coated with PAni-PO.

\begin{tabular}{|c|c|c|c|c|c|}
\hline & $\begin{array}{c}I_{\text {corr }} \\
\mu \mathrm{A} \mathrm{cm}^{-2}\end{array}$ & $\begin{array}{c}E_{\text {corr }} \\
\mathrm{mV} \text { versus SCE }\end{array}$ & $\begin{array}{c}b_{a} \\
\mathrm{mV} \mathrm{dec}^{-1}\end{array}$ & $\begin{array}{c}b_{c} \\
\mathrm{mV} \mathrm{dec}^{-1}\end{array}$ & Rate $_{\text {corr }}$ \\
\hline Blank & 34.16 & -721.0 & 101.7 & 382.8 & 15.21 \\
\hline \multicolumn{6}{|c|}{ PAni-PO $\left(\times 10^{-1} \mathrm{M}\right)$} \\
\hline 0.5 & 10.34 & -491.5 & 60.41 & 133.0 & 4.72 \\
\hline 1.0 & 6.0 & -417.0 & 60.0 & 382.0 & 2.74 \\
\hline 1.5 & 5.28 & -623.0 & 100.8 & 272.0 & 2.41 \\
\hline
\end{tabular}

TABLE 2: Electrochemical impedance data deduced from Nyquist plots by fitting to an equivalent circuit in Figure 5.

\begin{tabular}{lccc}
\hline & $\begin{array}{c}R_{\mathrm{ct}} \\
\Omega \mathrm{cm}^{2}\end{array}$ & $\begin{array}{c}C_{\mathrm{dl}} \\
\mathrm{F} \mathrm{cm}^{-2}\end{array}$ & $\begin{array}{c}R_{s} \\
\Omega \mathrm{cm}^{2}\end{array}$ \\
\hline $\begin{array}{l}\text { Blank } \\
\text { PAni/PO }\left(\times 10^{-1} \mathrm{M}\right)\end{array}$ & 336.8 & $1.201 \times 10^{-3}$ & 5.2 \\
0.5 & 521.5 & $1.643 \times 10^{-5}$ & 11.5 \\
1.0 & 1713.0 & $1.659 \times 10^{-5}$ & 11.8 \\
1.5 & 3542 & $8.986 \times 10^{-6}$ & 195.6 \\
\hline
\end{tabular}

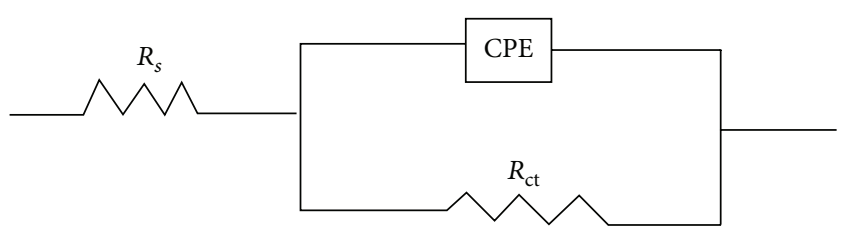

FIGURE 5: Randles circuit used for polyaniline/palm/oil blend coating on mild steel electrode.

resin. The results of open circuit potentials indicate that the blend has more positive oxidation potential than polyaniline reported in the literature. More studies are needed for elucidating the mechanism of protection.

\section{Conflict of Interests}

The authors do not have direct financial relation with the commercial identities mentioned in the paper despite using the Potentiostat/Galvanostat/ZRA (Gamry, Reference 600), Perkin Elmer Spectrophotometer. Therefore, the authors declare that there is no conflict of interest regarding the publication of this paper.

\section{Acknowledgments}

The authors are thankful to the School of Chemical Sciences, Universiti Sains Malaysia (USM), for providing the necessary research facilities. Mohd Rashid also thanks the Department of Chemistry, AMU, Aligarh, for providing necessary facilities.

\section{References}

[1] G. Mengoli, M. T. Munari, P. Bianco, and M. M. Musiani, "Anodic synthesis of polyaniline coatings onto fe sheets," Journal of Applied Polymer Science, vol. 26, no. 12, pp. 4247-4257, 1981.

[2] D. W. DeBerry, "Modification of the electrochemical and corrosion behavior of stainless steels with an electroactive coating," Journal of the Electrochemical Society, vol. 132, no. 5, pp. 10221026, 1985.

[3] D. W. DeBerry, "Modification of the electrochemical and corrosion behavior of stainless steels with an electroactive coating," Journal of the Electrochemical Society, vol. 132, no. 5, pp. 10221026, 1985.

[4] B. Wessling, "Passivation of metals by coating with polyaniline: corrosion potential shift and morphological changes," Advanced Materials, vol. 6, no. 3, pp. 226-228, 1994.

[5] D. E. Tallman, G. Spinks, A. Dominis, and G. G. Wallace, "Electroactive conducting polymers for corrosion control, part 1: general introduction and a review of non-ferrous metals," Journal of Solid State Electrochemistry, vol. 6, no. 2, pp. 73-84, 2002.

[6] T. Ohtsuka, "Corrosion protection of steels by conducting polymer coating," International Journal of Corrosion, vol. 2013, Article ID 915090, 7 pages, 2012.

[7] W. Lu, R. L. Elsenbaumer, and B. Wessling, "Corrosion protection of mild steel by coatings containing polyaniline," Synthetic Metals, vol. 71, no. 1-3, pp. 2163-2166, 1995.

[8] D. Sazou and C. Georgolios, "Formation of conducting polyaniline coatings on iron surfaces by electropolymerization of aniline in aqueous solutions," Journal of Electroanalytical Chemistry, vol. 429, no. 1-2, pp. 81-93, 1997.

[9] A. Talo, O. Forsen, and S. Ylasari, "Polyaniline/epoxy coatings with good anti-corrosion properties," Synthetic Metals, vol. 85, no. 1-3, pp. 1333-1334, 1997.

[10] N. Ahmad and A. G. MacDiarmid, "Inhibition of corrosion of steels with the exploitation of conducting polymers," Synthetic Metals, vol. 78, no. 2, pp. 103-110, 1996.

[11] A. Talo, O. Forsen, and S. Ylasaari, "Corrosion protective polyaniline epoxy blend coatings on mild steel," Synthetic Metals, vol. 102, no. 1-3, pp. 1394-1395, 1999.

[12] J. R. Santos Jr., L. H. C. Maltoso, and A. J. Motheo, "Investigation of corrosion protection of steel by polyaniline films," Electrochimica Acta, vol. 43, no. 3-4, pp. 309-313, 1998.

[13] A. P. Srikanth, V. Raman, S. Tamilselvi, S. Nanjundan, and N. Rajendran, "Electropolymerization and corrosion protection of polyaniline and its copolymer on carbon steel," Anti-Corrosion Methods and Materials, vol. 55, no. 1, pp. 3-9, 2008.

[14] J. L. Camlet, J. C. Lacoroix, S. Aeiyach, K. Chane-Ching, and P. C. Lacaze, "Electrosynthesis of adherent polyaniline films on 
iron and mild steel in aqueous oxalic acid medium," Synthetic Metals, vol. 93, no. 2, pp. 133-142, 1998.

[15] R. Rajagopalan and J. O. Iroh, "Development of polyanilinepolypyrrole composite coatings on steel by aqueous electrochemical process," Electrochemica Acta, vol. 46, no. 16, pp. $2443-$ 2455, 2003.

[16] M. Kralkic, K. Z. Mandic, and L. J. Duic, "Inhibition of steel corrosion by polyaniline coatings," Corrosion Science, vol. 45, no. 1, pp. 181-198, 2003.

[17] N. M. Martyak, P. McAndrew, J. E. McCaskie, and J. Dijon, "Electrochemical polymerization of aniline from an oxalic acid medium," Progress in Organic Coatings, vol. 45, no. 1, pp. 23-32, 2002.

[18] H. Bhandari, S. Sathiyanaranayan, V. Choudhary, and S. K. Dhawan, "Synthesis and characterization of proccessible polyaniline derivatives for corrosion inhibition," Journal of Applied Polymer Science, vol. 111, no. 5, pp. 2328-2339, 2009.

[19] B. Wessling, "Corrosion prevention with an organic metal (polyaniline): surface ennobling, passivation, corrosion test results," Materials and Corrosion, vol. 47, no. 8, pp. 439-445, 1996.

[20] B. Yao, G. Wang, J. Ye, and X. Li, "Corrosion inhibition of carbon steel by polyaniline nanofibers," Materials Letters, vol. 62, no. 1213, pp. 1775-1778, 2008.

[21] S. Sathiyanarayanan, S. K. Dhawan, D. C. Trivedi, and K. Balakrishnan, "Soluble conducting poly ethoxy aniline as an inhibitor for iron in HCl," Corrosion Science, vol. 33, no. 12, pp. 1831-1841, 1992.

[22] K. G. Thompson, C. J. Bryan, B. C. Benicewicz, and D. A. Wrobleski, "Corrosion-protective coatings from electricallyconducting polymers," Los Alamos National Laboratory Report LA-UR-92-360, 1992.

[23] D. A. Wroblewski, B. C. Bencewicz, K. G. Thompson, and C. J. Bryan, "Corrosion resistant coatings from conducting polymers," Polymer Preprints, vol. 35, no. 1, pp. 265-270, 1994.

[24] A. Subramania and S. L. Devi, "Polyaniline nanofibers by surfactant-assisted dilute polymerization for supercapacitor applications," Polymers for Advanced Technologies, vol. 19, no. 7, pp. 725-727, 2008.

[25] K. Jutner, Electrochimica Acta, vol. 35, p. 1150, 1990.

[26] X. R. Zeng and T. M. Ko, "Structures and properties of chemicallyreduced polyanilines," Polymer, vol. 39, no. 5, pp. 1187-1195, 1998.

[27] S. Haruyama and T. Tsuru, "Electrochemical impedance measurement for corrosion monitoring," in Proceedings of the Symposium on Futuristic Aspect in Electrochemical Science \& Technology Organized by Society for Advancement of Electrochemical Science and Technology, at Central Electrochemical Research Institute, p. 9, Karaikudi, India, March 1981.

[28] T. Paskossy, "Impedance of rough capacitive electrodes," Journal of Electroanalytical Chemistry, vol. 364, pp. 111-125, 1994.

[29] W. Fawcett, R. Kovacova, A. Mathew, and A. Fosse, "Application of the ac admittance technique to double-layer studies on polycrystalline gold electrodes," Journal of Electroanalytical Chemistry, vol. 326, no. 1-2, pp. 91-103, 1992.

[30] F. N. Donahue and K. Nobe, "Theory of organic corrosion inhibitors III. LFER correlation of inhibition of Armco iron by ring-substituted anilines," Journal of the Electrochemical Society, vol. 114, no. 10, pp. 1012-1015, 1967.

[31] P. J. Kinlen, D. C. Silverman, and C. R. Jeffreys, "Corrosion protection using polyaniline coating formulations," Synthetic Metals, vol. 85, no. 1-3, pp. 1327-1332, 1997.
[32] F. Bentiss, M. Lebrini, M. Lagrenée, M. Traisnel, A. Elfarouk, and H. Vezin, "The influence of some new 2,5-disubstituted 1,3,4-thiadiazoles on the corrosion behaviour of mild steel in $1 \mathrm{M} \mathrm{HCl}$ solution: AC impedance study and theoretical approach," Electrochimica Acta, vol. 52, no. 24, pp. 6865-6872, 2007. 

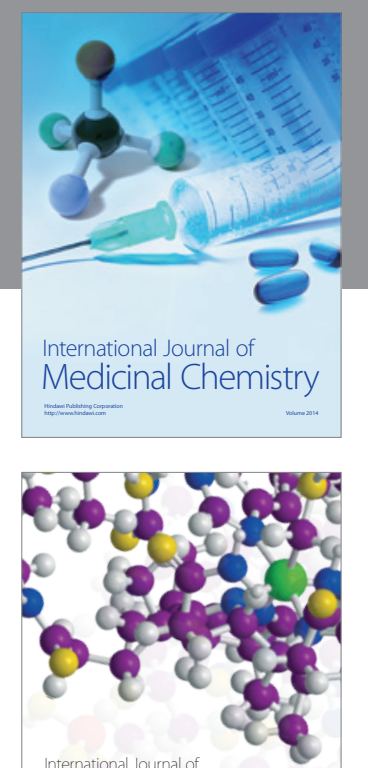

\section{Carbohydrate} Chemistry

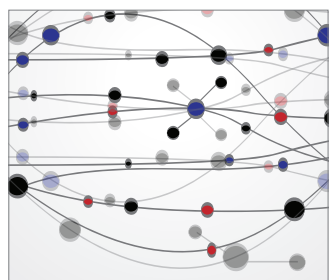

The Scientific World Journal
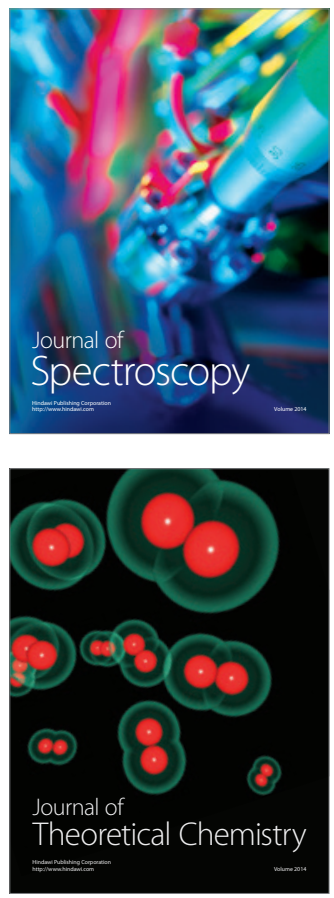
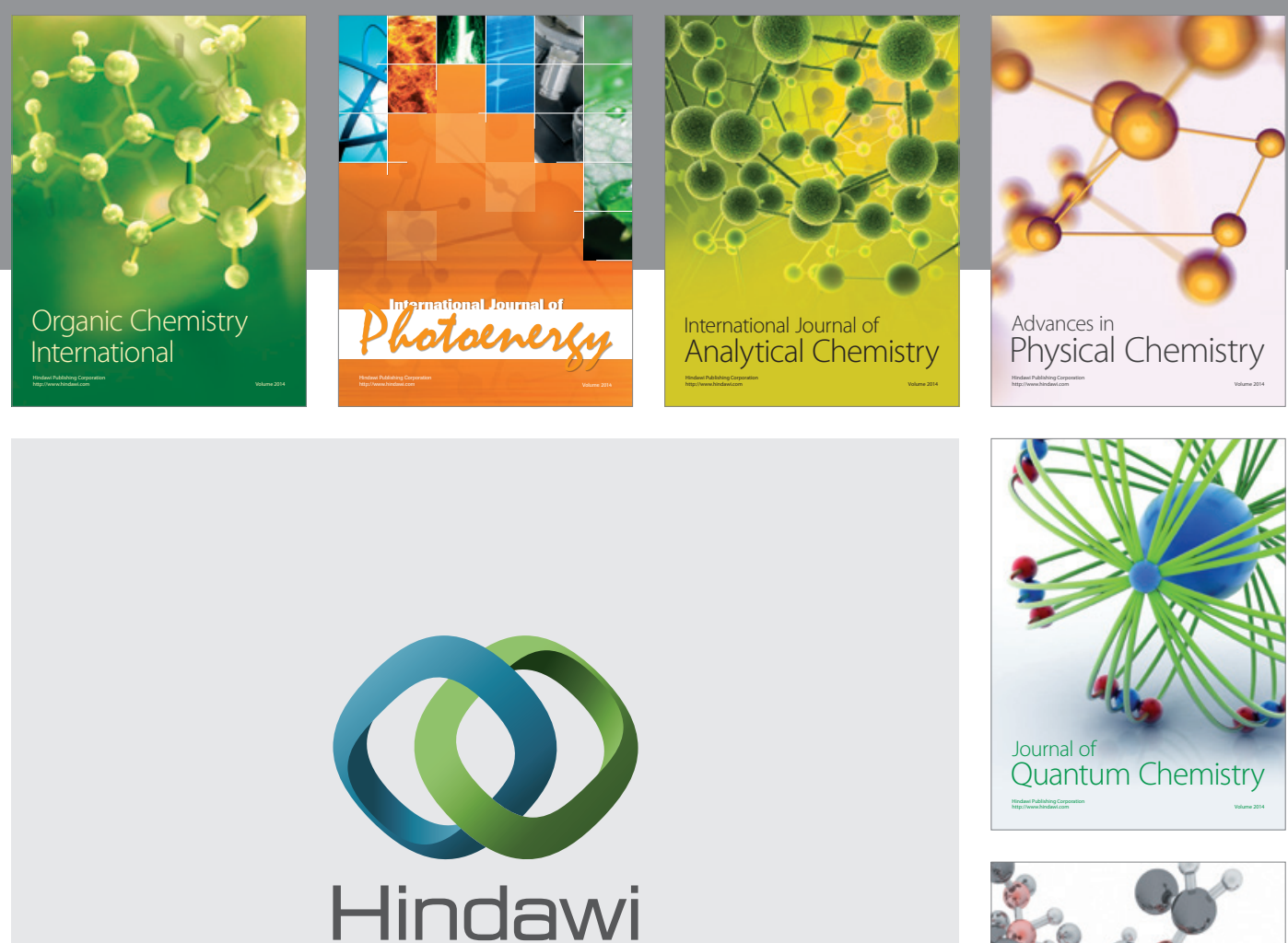

Submit your manuscripts at

http://www.hindawi.com

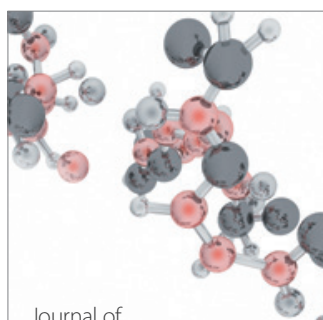

Analytical Methods

in Chemistry

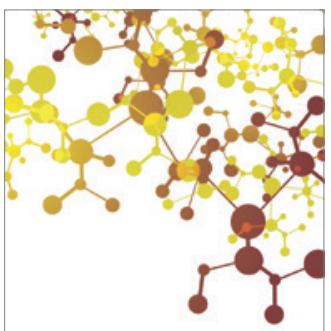

Journal of

Applied Chemistry

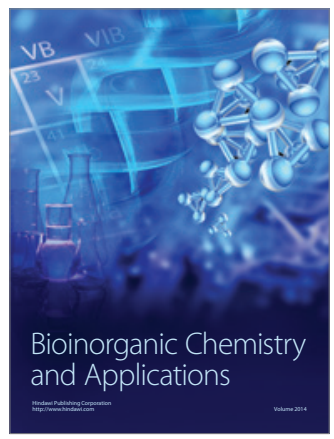

Inorganic Chemistry
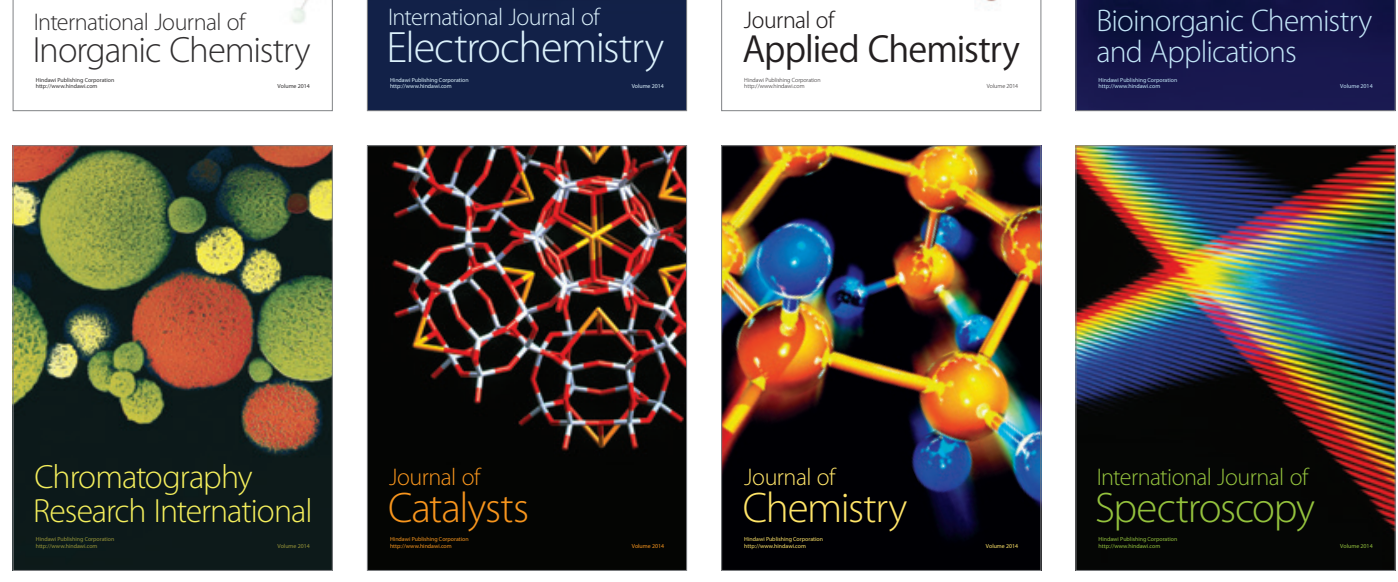